\title{
Imaginarios y representaciones en la tradición oral africana y latinoamericana
}

\author{
Imaginary and representations in the African \\ and Latin American oral tradition
}

\section{Daiana Nascimento dos Santos}

Universidad de Santiago de Chile. Santiago, Chile

estrelinha95@hotmail.com

$\mathrm{D}$ urante mucho tiempo la historia de África ha sido una compleja y ambivalente construcción discursiva que ha recibido una atención teórica y crítica muy contingente en el contexto occidental, aunque en las últimas décadas ha tenido significativas reflexiones en torno al tema. De ahí la importancia de considerar los discursos que intentan reflexionar sobre esta historia, la emergencia de ponerla en relieve, de analizar las cosmovisiones que conforman este discurso histórico y enunciativo.

Es un discurso que pone de relieve la coyuntura "Africa tiene una historia", cuya mayor notabilidad se orienta en la reescritura y relectura de esta historia (Ki-Zerbo, 1982: 23). Se trata de un proceso que pretende considerar las perspectivas, relatos, imágenes, elementos arqueológicos y actores sociales otros que han sido ocultados o que fueron estratégicamente perdidos (Ki-Zerbo, 1982: 24).

Puesto que el discurso histórico sobre África ha sido enmascarado y desfigurado en una perspectiva de poder que ofrece un imaginario repleto de oscuridades e incógnitas, cuya idea remite a una "desresponsabilización"1 histórica presente en las cosmovisiones sobre este continente, a la vez este discurso de poder remite a una construcción ideológica que se evidencia en la alteridad presente en algunos discursos sobre la historia de África (Bha-

${ }^{1}$ Se trata del concepto propuesto por el sociólogo español Imanol Zubero, parafraseado por M'bare N'gom Faye en el prologo del libro: Letras afroperuanas. Creación e identidad (Campos y Respaldiza, 2010). 
bha, 2002: 91).

Esta otredad se legitima en los juicios circunstanciales y prejuiciosos que orienta las consideraciones inferiores e imperfectas de un individuo sobre "el otro" y las cosmovisiones que hacen parte de este imaginario (Hall y Du Gay, 2003: 187). Esta otredad se enmarca a través de connotaciones rígidas y estereotipos cargados de ignorancia que se configuran en ideas y conceptos construidos dentro del discurso y fuera de él (Hall y Du Gay, 2003: 18). A la vez, esta otredad impone una perspectiva de discurso de poder, puesto que esta objetividad intenta anular lo que se entiende como amenaza (Hall y Du Gay, 2003: 33). Este presupuesto se enmarca en el discurso de poder que ha intentado anular y desconsiderar el pasado histórico africano, por razón de las diferencias que componen este imaginario. De ahí que el poder evidenciado en estos discursos se legitima a través de una alocución que hace hincapié en el discurso científico con el afán de subyugar y revocar las cosmovisiones que conforman este imaginario (Walsh, 2007: 104-106).

Se trata, por lo tanto, de sujetos e imaginarios considerados diferentes o paradójicos en la conceptualización que orienta ciertos paradigmas legitimándolos como universales (Hall y Du Gay, 2003: 19).

Por otro lado, esta perspectiva de deconstrucción discursiva e imaginaria sobre África se enmarca a través de significativos textos de historiadores africanos que sugieren la primicia de estudiar y reconocer esta historiografía.

Se trata entonces de importantes estudios que han intentado traer a la luz un pasado histórico, a través del rescate y valoración de la tradición oral africana, de las excavaciones arqueológicas y de los documentos históricos.

Al hablar de estos presupuestos, se hace importante poner de relieve el proceso de descolonización de África, puesto que se evidencia una intensa reivindicación de las raíces africanas que conlleva a una revalorización del legado y de africanidad negada (Miampika, 2000: 36). Estos procesos de reivindicación se extienden a varios rincones de Europa, América Latina, Estados Unidos y África.

En la búsqueda de una relectura de la historia africana surgen intensos polos culturales e intelectuales donde se pretende recobrar la participación legítima del negro en la Historia Contemporánea y, principalmente, hacer notar la validez de esta actuación. Además, Miampika explica que es necesario que haya una reconciliación de este sujeto con su pasado histórico y consigo mismo (2000: 36). A partir de ahí es posible hacer un viaje a la memoria histórica en la huella del pensamiento expresado por Aimé Césaire en su Cahier d'un retour au pays natal.

Hablar de un viaje a la memoria es proponer un vínculo entre este pasa- 
do y la cultura, las tradiciones y las cosmovisiones que éste ha generado. A partir del rescate de este legado histórico y mítico se hace posible recrear un imaginario que se evidencia en la tradición oral africana y principalmente en las producciones literarias y artísticas que han propuesto este supuesto rescate histórico. A la vez, la tradición oral africana se evidencia como significativo hincapié para la reconstrucción de su Historia, este elemento vehicula su perpetuación que ha sido transmitida oralmente a través de los tiempos (Hampaté Ba 1982: 184).

La tradición oral se enmarca como el conocimiento total, que configura al hombre en su totalidad y lo define como un depositario de conocimiento que interactúa constantemente con el Todo. Se trata de revestir este discurso oral como elemento mágico y divino, cuya validez hace hincapié en los discursos tradicionales de pueblos ágrafos.

En este contexto, la tradición configura al hombre en su totalidad cuya cosmovisión esculpe el alma africano a través del rescate de la memoria. A la vez, esta práctica ha recibido consideraciones peyorativas del discurso de poder, puesto que la validez de la oralidad sorprende al espíritu cartesiano acostumbrado a la categorización minuciosa (Hampaté Ba 1982: 187).

Por otro lado, en el contexto latinoamericano los ibéricos subyugaron el poder de la escritura sobre las tradiciones orales de los pueblos autóctonos en el periodo del "descubrimiento" (Lienhard, 1991: 25). En este entonces, el poder atribuido al texto escrito se legitimaba como expresión divina, ya que esta escritura se legitima como instrumento de poder puesto al servicio de quienes la mantienen y la controlan.

En el contexto de la historia africana tradicional y de los pueblos autóctonos de América Latina, esta herramienta juega un papel de poder que se valida como único medio de comunicación oficial, conllevando a una sustracción del sistema gráfico o de los signos concernientes a las tradiciones orales de estos pueblos (Lienhard, 1991: 30-31).

La validez de esta escritura deniega la tradicionalidad al olvido y a la desmemorización de un pueblo, cuyo énfasis se funde en las cosmovisiones orales y en el papel que juegan los griots, de los tradicionalistas africanos y los sabios indígenas, en los relatos, las narrativas visuales, los lenguajes gestuales, rituales y simbólicos con que se transmite y recrea esta tradición.

Se trata, por lo tanto, de considerar a estos sujetos como depositarios de conocimiento, de la memoria y principalmente del patrimonio cultural de la historia africana y latinoamericana. Aunque se ha evidenciado en el África de hoy un intenso quiebre en esta transmisión oral, gracias al exilio y otros factores que conllevan a esta ruptura memorial. A la vez, hablar de 
oralidad en estas culturas es considerarla de manera auténtica y prestigiosa, cuyo desarrollo y diversificación hace viable cumplir funciones sociales de su cosmovisión y estructuras productivas que no son pertinentes a las culturas de predominancia gráfica (Lienhard, 1991: 30).

Estas tradiciones se expresan a través de expresiones visuales, orales, gestuales y simbólicas que conservan, cuentan y reproducen las cosmovisiones históricas y memoriales que todavía no se han narrado (Soni Labou Tansi et al., 2000: 57-69).

También es importante poner en duda el posible éxito que se podría generar con el reconocimiento de estos imaginarios y principalmente, la desmitificación de algunos estereotipos que han sido construidos sobre la historia de África, se refiere a conceptos que han sido establecidos como verdades universales vinculados a la idea de otredad (Bernd, 1988: 11).

Por otro lado, se hace necesario cuestionar: ¿es posible lograr que el Uno (Occidente) encuentre al Otro (África y América Latina) en la diversidad (Miampika, 2000: 33)? En esta búsqueda de encontrar a este Otro en la diversidad se hace necesario rescatar la historia, la memoria, la identidad y la cultura múltiple de sujetos que anhelan construir su propio legado a partir de las voces de hombres y mujeres africanas (indígenas, en el caso de América Latina), que reivindican su lugar de enunciación en un África múltiple y plural (Miampika, 2000: 49).

Esta búsqueda por su lugar de enunciación sitúa y acerca esta reivindicación africana al contexto latinoamericano, cuyos diálogos se entrecruzan en un clamor de esperanza por un África -y América Latina- que se busca a sí misma (Miampika, 2000: 43).

En esta perspectiva, surgen los "griots contemporáneos" que constituyen el papel de mediador, depositario y guardián de la historia, las genealogías, del legado y de las tradiciones orales de sus imaginarios (Cordones-Cook, 2009: 13). Asimismo, estos sujetos se apropian del papel desarrollado por los sabios tradicionales que todavía siguen cumpliendo el rol de depositario de conocimiento en los varios rincones del continente africano y latinoamericano.

Por otro lado, estos "griots contemporáneos" hacen escuchar sus voces a través de la escritura, de la yuxtaposición de elementos tradicionales africanos y occidentales (Werewere Liking) para narrar sus versiones sobre el proceso de independización africano, las pesadillas de las fraudulentas independencias, los exilios, los imaginarios, las cosmovisiones y la redefinición del lugar epistemológico de las plumas femeninas en el África actual. La propuesta de estos "griots contemporáneos" es releer, redescubrir y conservar 
el legado memorial de la historia africana a través de los relatos de vida que conforman estos imaginarios.

En esta perspectiva, se hace importante conservar el rol desarrollado por estos sujetos en la contemporaneidad africana y latinoamericana, cuyo principal objetivo es ir en búsqueda de las memorias silenciadas inscribiéndolas en un eje tangible entre un pasado vinculado a la trata africana y el imaginario histórico que éste ha generado en África, cuya relevancia permite proponer diálogos con América Latina.

Se trata, entonces, de yuxtaponer lo mítico y lo valido del discurso oral africano y latinoamericano que se funde en la memoria, rescate y legitimación de un imaginario que se evidencia en las letras de Sony Labou Tansi, Paul Dakeyo, Nancy Morejón, Nicolás Guillén, Werewere Living (Miampika, 2000: 54-123) y tantos otros que fecundan con sus palabras posibles imaginarios.

Por lo tanto, se hace urgente conservar el papel de quienes son los depositarios de las tradiciones orales africanas, quechuas, mapuches, tupinambás, etc. Y principalmente, hacer notar que este legado forma parte de un patrimonio histórico que no puede desaparecer del contexto africano y latinoamericano, pues esto afectaría a la belleza y solidez discursiva que atraviesa el legado de estos pueblos.

Finalmente, estas perspectivas consideran y convierten las identidades variables, lenguas, culturas, etnias, historias y cosmovisiones en un discurso que está por construir sobre la importancia de la oralidad para la constitución histórica de África y América Latina.

\section{REFERENCIAS}

Bernd, Zilá. 1988. O que é negritude? São Paulo: Editora Brasiliense.

Bhabha, Homi. 2002. El lugar de la cultura. Buenos Aires: Editorial Manantial.

Campos, José y Respaldiza, José (Eds). 2010. Letras afroperuanas. Lima: Fondo Editorial del Congreso del Perú.

Cordones-Cook, Juanamaría. 2009. Soltando amarras y memorias: mundo y poesía de Nancy Morejón. Santiago: Editorial Cuarto Propio.

Hall, Stuart y Du Gay Paul (Eds). 2003. Cuestiones de identidad cultural. Buenos Aires: Amorrortu.

Hampaté Ba, Amadou. 1982. La tradición viva. Historia general de Africa: Metodología y prehistoria de Africa. París: UNESCO. 
Ki-Zerbo, J. 1982. Introducción a la Historia general de África. Metodología y prehistórica africana. vol. I, Jeune Afrique/Unesco, pp. 21-43.

Lienhard, Martin. 1991. La voz y su huella. Hanover: Ediciones del Norte.

Miampika, Landry-Wilfrid. 2000. Africa a varias voces: cantos y ecos. Voces africanas. Madrid: Editorial Verbum.

Soni Labou Tansi, Paul Dakeyo, Cossy Guenou, Joseph Anouma, Werewere Liking. 2000. Voces africanas. Madrid: Editorial Verbum, pp.54-123.

Walsh, Catherine. 2007. “¿Son posibles unas ciencias sociales/culturales otras? Reflexiones en torno a las epistemologías decoloniales?”, en Revista Nómadas 26, pp. 102-113. 